\title{
A intertextualidade camoniana em ...Onde Vaz, Luís? (1983) de Jaime Gralheiro ou Luís Vaz de Camões revisitado no teatro português contemporâneo
}

\section{Resumo:}

O objetivo do artigo é a comparação d'Os Lusiadas (1572) de Luís Vaz de Camões e de ... Onde Vaz, Luís (1983) de Jaime Gralheiro, mostrando os processos do enxerto narrativo de um padrão epopeico no hipertexto dramático, obrado através de "um mosaico de citações". Trata-se de uma transformação genérica muito produtiva estética e ideologicamente, com traços visíveis de paródia, disfarce, pastiche, transposição narrativa de mais de um texto só e de muitos escritores quinhentistas portugueses (inclusive Fernão Mendes Pinto, António Ferreira, Pedro de Andrade Caminha, Damião de Góis, Gil Vicente) vinculados a uma peça jocosa, tanto trágica como grotesca, concebida segundo a crítica social e de cariz ideológico Brechteano. $\mathrm{O}$ artigo apresenta uma mostra de múltiplas relações entre o hipotexto primário e os textos dele derivados, patenteando o fim do texto em causa em muitas obras e literatura portuguesa de vários autores de romances e peças de teatro. O heróico hipotexto vs. os hipertextos são desdobrados em refabulações dramáticas e novelescas pós-modernas (José Saramago inclusive!). Um outro estudo ainda do imaginário ao abrigo da revisitação de literatura portuguesa é possível em relação à história contemporânea e à existência humana, com as fronteiras espácio-temporais e géneros literários apagados na "lotaria intertextual" de Camões e seus avatares quanto aos autores ficcionais e protagonistas. Um diagnóstico do hic et nunc (agora mesmo!) está a ser produzido de um 
modo metodologicamente consistente segundo os clássicos, de intertextualidade focalizada na dramaturgia e escrita romanesca em Portugal no ocaso do milénio antecedente, com a revolução dos cravos no pano de fundo e o corolário da pós-democracia acompanhando o processo analítico empreendido.

Palavras-chave: literatura, teatro, história, intertextualidade, Revolução dos Cravos

\begin{abstract}
:
Camoenian Intertextuality in ...Onde Vaz, Luís? (1980) by Jaime Gralheiro or Luís Vaz de Camões Revisited in the Contemporary Portuguese Theater The objective of the article is a comparison between Os Lusiadas/The Lusiads (1572) by Luís Vaz de Camões and ...Onde Vaz, Luís (1983) by Jaime Gralheiro, showing the processes of narrative incorporation of an epic pattern into the dramatic hypertext, made through a "mosaic of quotations". The discussion attends to the generic transformation, a very productive one in terms of aesthetics and ideology, with visible traits of parody, disguise, pastiche, narrative transposition of more than one unique text but many of them by various Portuguese authors of the XVIth century (including Fernão Mendes Pinto, António Ferreira, Pedro de Andrade Caminha, Damião de Góis, Gil Vicente) ment for a jocular dramatic piece, both tragic and grotesque, conceived out of social criticism and according to a Brechtean ideological character. The article shows a sample of multiple relations between the primary hypotext and the texts derivated out of it, confirming the present paper's aim in many works of Portuguese literature writers, of prose and theater writings. The heroic hypotext vs. the hypertexts are unfolded in dramatic and novelesque post-modern refabulations (José Saramago included!). Another study of the imaginary makes the realm of revisiting the Portuguese literature is possible in relation to contemporary history and human existence, with space-and-time frontiers and literary genres extinguished in the "intertextual lottery" of Camões and his metamorfoses with regard to fictional authors and protagonists. A diagnosis of hic et nunc (just now!) is being produced in a methodologically consistent way according to the classics of intertextuality focused on dramatic and romanesque writings in Portugal in the decline of the former century. The Carnations' Revolution in the background and the revolutionary democratic aftermath accompanying the undertaken analytic process.
\end{abstract}

Keywords: literature, theater, history, intertextuality, Carnations' Revolution 
Para o Dr. Jakub Jankowski, meu Chefe e ex-estudante

"ALUNOS: Eu quando for grande quero ser Luís de Camões"

(Gralheiro, 1983: 18)

\section{Intertextualidade, metodologia, objetivo, vozes e dramatis personae}

Como fundamentação teórica para a realização deste trabalho, exploraremos o conceito de intertextualidade, cunhado por Julia Krišteva, segundo a qual "tout texte est un mosaïque de citations". O pressuposto de que há um "intercâmbio discursivo" entre as obras literárias (Krišteva, 2000: 85), considerando todo o vasto contexto histórico, literário e cultural que as envolve, sustenta a aproximação que fazemos entre ...Onde Váz, Luís?, obra dramática de Jaime Gralheiro ${ }^{1}$ escrita em 1980 para comemorar o $4^{\circ}$ centenário da morte de Camões, encenada "de forma buliçosa, festiva e envolvente" (Reis, 2005: 227) em setembro de 1981 no Teatro do Picadeiro Mirita Casimiro pela Companhia do Teatro Experimental de Cascais e Os Lusíadas (1572), um poema épico, heróico e nacional dos portugueses traduzido em polaco e infiltrado na Polónia no contexto do classicismo e romantismo².

${ }^{1}$ Jaime Gralheiro (1930-2014) foi dramaturgo, advogado, destacado lutador anti-fascista e defensor dos baldios, autor de peças como: ...Onde Vaz, Luís?, Arraia-Miúda, Na Barca com Mestre Gil e da peça infantil Farruncho. Foi sempre um firme lutador pela liberdade, tendo participado ativamente antes do 25 de Abril no combate ao fascismo e na oposição democrática. Nos últimos anos da vida publicou obras de ficção narrativa.

${ }^{2}$ Recentemente, tivemos a possibilidade de falar sobre a receção d'OS Lusíadas aquando do congresso internacional A Volta ao Mundo em 40 Anos. Encontros e reencontros em língua portuguesa, organizado em 12-13 de abril de 2018 no Instituto de Estudos Ibéricos e Iberoamericanos da Universidade de Varsóvia, numa comunicação subordinada ao tópico $O$ poder misterioso da (re)apropriação de Os Lusíadas na Polónia ou Camões dirige-se aos seus contemporâneos. Cf. Kalewska, 2019. 
Logo, a criação literária de um autor é forçosamente o reflexo de outras leituras e de modelos literários, de um cruzamento de pensamentos, valores e ideais e vive indissociável do contexto político, cultural e religioso (Vieira, 2008: 465-556). A influência de Os Lusíadas no ...Onde Vaz, Luis? é um exemplo deste processo considerado dentro do sistema literário e do imaginário identitário português.

Uma vez que há uma inter-relação entre o hipotexto ou um texto posterior e o texto dele derivado (Genette, 1982; 1996), chamado hipertexto, envolve os processos de transformação (paródia, disfarce, transposição, pastiche) ou de imitação (reprodução), juntamente com a voz de um comentário (ou de um comentador/ narrador/ narratário/ personagem) inscrito na obra, a hipotextualidade camoniana e $O s$ Lusíadas servirá, no nosso entender, de ponto de partida para uma metodologia comparativista, que colocará em diálogo não só a obra do autor português da época do Renascimento, como ainda as personagens e as vozes de vários mestres seus contemporâneos (António Ferreira, Pedro de Andrade Caminha, Fernão Mendes Pinto, D. João III, Damião de Góis, assim como toda uma plêiade ou "quase uma romaria" de inquisidores, pregoeiros, mercadores, feitores da Casa da Índia, bufarinheiros, regateiras, damas e criadas).

Para realizar o cotejo intertextual (e também intercultural) de $O s$ Lusíadas percebidos como hipotexto, ou o hipotexto camoniano, do ...Onde Vaz, Luís? na sua função de um texto introduzido nos contextos camonianos com a ousadia paródica da escrita polifónica e pluridiscursiva é necessário conhecer a fundo a epopeia lusa, a vida do seu autor, as circunstâncias históricas que condicionaram a obra. Sem esquecer a rica receção da epopeia camoniana nas nossas comunicações anteriores, passaremos à apresentação da peça teatral em questão como uma ficção dramatúrgica ou o hipertexto enxertado na epopeia (desempenhando Os Lusíadas a sua função hipotextual da obra original) e num mosaico de referências a textos quinhentistas para o deciframento e a caracterização das ocorrências intertextuais presentes.

Ressoam, pois, em ...Onde Vaz, Luís? trechos de Os Lusíadas, uma grande quantidade de imitações do próprio Camões, como por exemplo o soneto Amor é fogo que arde sem se ver, o Auto dos Anfitriões 
e passagens de autos de Gil Vicente: o Auto da Índia e o Auto de Inês Pereira. Todos estes textos ressoantes na peça aparecem sob a forma de uma citação, alusão, ou de um inter-texto reefabulado tendo como base Os Lusíadas de Camões (ou a Peregrinação de Fernão Mendes Pinto) ou na qualidade de um novo texto, de forma a ser vista a obra dramática em causa sob um novo prisma, ou seja, pela ótica de paródia, riso, cómico e grotesco. Trata-se, no dizer de Maria Alzira Seixo, de "hibridismo des-organizado", patente, por exemplo, na relação entre as Cartas Portuguesas (1669) e Novas Cartas Portuguesas (1972) quanto ao "hipotexto marianista" (ap. Mendes, 2006: 295).

A intertextualidade estabelecida na peça de Jaime Gralheiro assume um caráter didático e político, uma vez que a peça toma partido da ótica pós-moderna, i.e., não apresenta a verdade dos factos sob o ângulo da história oficial, ou seja, aquele poeta que propagou a Fé e o Império. "O príncipe dos poetas portugueses"3 "o épico da raça"4, o autor d'Os Lusiadas ou "da Bíblia da pátria” (Gralheiro, 1983: 14), o portador das virtudes inabaláveis (aliás esquecidas e não praticadas) quatrocentos e quarenta anos passados depois da sua morte é apresentado em contrapartida ao "aldrabão" Fernão Mendes Pinto e muitos outros fingidores seus contemporâneos.

Deturpado, re-apropriado, furtado é pois o significado de Os Lusíadas, heróico hipotexto esse desdobrado em mil e um hipotextos menores, passíveis de "mudança" (como canta o cego cauteleiro na cena de abertura da peça) ou da interpretação truncada da parte do Professor Universitário, do Político e dos seus ouvintes, discípulos e interpretadores. A literatura, pois, assim como o teatro, FAZ-SE com aldrabões, fingimentos e mentiras, ao contrário, talvez, da história e da política ${ }^{5}$. O hipotexto camoniano ou a recriação de Luís Vaz de Camões, mais do que um ideal épico, ajuda a desenvolver um outro imaginário sobre

3 "PROFESSORA: Luís Vaz de Camões é o príncipe dos poetas portugueses. Luís Vaz de Camões nasceu na cidade de Lisboa, em 1520." (Gralheiro, 1983: 14).

4 "POLÍTICO (na Tribuna da Assembleia Nacional): Luís Vaz de Camões, o épico da raça, sr. Presidente e srs. Deputados!” (Gralheiro, 1983: 14).

5 "POLÍTICO: A história não se faz com aldrabões." (Gralheiro, 1983: 19). 
a História e, em geral, sobre a existência humana, que dilui fronteiras e faz deslocar os discursos da historiografia, bem como de outros discursos oficiais.

\section{A lotaria intertextual de Camões}

Jaime Gralheiro construiu a sua peça com o intuito de reler o século XVI sob a luz de uma perspetiva crítica do século XX, contribuindo com certeza para o desmoronamento do mito que sempre atravessou Os Lusíadas e a vida de Camões. O dramaturgo não sucumbiu, pois, à reverência de preservar ou cultuar o mito camoniano, a exemplo do que fizeram muitos outros autores ${ }^{6}$. Esta perspetiva crítica do autor pode ser evidenciada no enunciado feito pelo Chefe da Trupe na cena $\mathrm{V}$ do primeiro ato:

CHEFE DA TRUPE (que era o cauteleiro): Respeitável público, senhoras e senhores, vamos aqui apresentar a farsa dos ladrões, putas e mentirosos que é um auto de grande moralidade onde cabemos todos, uns melhor do que os outros! ... (Os da Trupe acompanham com mímica o que ele for dizendo). Porque este mundo é um covil de ladrões, putas e mentirosos, se ninguém se vê, porque todos são para consigo como os próprios olhos que, vendo tudo, não se vêm a si mesmos (grande gargalhada). Direis que falo picante o lépido. E eu vos digo que assim é, mas que só me toca o zelo do bem comum e o aumento da monarquia de que sua alteza el rei e senhor ... (os outros dizem que se cale). Pronto! Se é mister que me cale, pois eu me calo e vamos pôr mãos à obra. Aqui ireis ver algumas grossas roubalheiras, putarias e mentiras que se cometeram em estes reinos. Só contaremos o que vimos ou lemos. Não cuidaremos de pesquisar autores nem formalidades. E se, em algum passo da história, discreparem as

${ }^{6}$ Cf. A. Monteiro, Camões (1848), Tipografia da Revista, Porto. D. Catarina de Ataíde (Natércia) espera, triste e desanimada, o regresso de Camões da Índia, o que acaba por acontecer mesmo na véspera da partida de D. Sebastião para Alcácer Quibir. Devido aos amores do Conde de Câmara Castanheira, escrivão da puridade. Devido a um engano, acaba por ser D. Catarina quem morre mesmo no momento da partida das naus para África. (Vasconcelos, 2003: 539). 
circunstâncias da narração e não se ajustarem em tudo com o sucedido, pouco vai nisso, porque, como diz o outro, o nosso intento não é deslindar pleitos para os sentenciar, senão que mostrar deformidades para as estranhar. (Chama pelos outros. Faz-lhes sinal para desdobrarem um grande painel. Os outros executam. No painel está um jovem poeta, Camões, cercado de ninfas e musas) (Gralheiro, 1983: 39).

Importa ressaltar aqui o duplo sentido assumido pela palavra "estranhar" na peça. Primeiramente, a palavra no seu sentido denotativo, refere-se à exprobação, à censura, ao pouco natural, àquilo que é oposto aos costumes, ou seja, diferente daquilo que narra a história oficial. Vista de outro modo, a palavra "estranhar" pode-se compreender no sentido conferido pela teoria do estranhamento, preconizado por alguns formalistas russos, ora do distanciamento, da singularização, da desfamiliarização ou mesmo da desautomatização da leitura de um texto literário (no nosso caso, do contexto cultural camoniano e hipertexto de Os Lusíadas). O desconhecido continua a ser explicado pelo conhecido, mas com o sentido inverso, como argumentava Victor Chklovski:

A finalidade da arte é dar uma sensação ao objecto como visão e não como reconhecimento; o processo da arte é o processo de singularização (ostraniene) dos objectos e o processo que consiste em obscurecer a forma, em aumentar a dificuldade e a duração da percepção. O acto de percepção em arte é um fim em si e deve ser prolongado; a arte é um meio de sentir o devir do objecto, aquilo que já se 'tornou' não interessa à arte. (Chklovski, 1999: 82).

Foi no tornar estranho, no anular da familiaridade da nossa posição ideológica para com Os Lusíadas e a vida de Camões - ao ponto de o mito camoniano se tornar estranho a nós mesmos - como também na duplicidade do sentido e na estratégia do distanciamento, que a peça em questão passou a ser a negação da negação do legado renascentista no Portugal pós-democrático. A dupla negação (do conhecido e do desconhecido) constitui, então, o truque ideológico e narrativo básico (e dramatúrgico, incluindo as didascálias) por meio do qual 
Gralheiro interpretou o século XVI em Portugal e a maneira como se processou a expansão da Fé e do Império: através das tramóias dos inquisidores, padres e delatores transformados em políticos e "chefes da trupe" contemporâneos. Dentro das técnicas discursivas empregadas pela peça percebe-se que existe um narrador que interfere no palco das ações, comentando-as e revezando muitas vezes com as falas de Camões (em efígie Pessoana do poeta-fingidor!), Garcia de Resende, Andrade Caminha Fernão Mendes Pinto, D. João III, Damião de Góis e o Mal Cozinhado. Trata-se do alter-ego narrativo da voz off ou de um anfitrião de um mundo às avessas ou do opositor das ações nobres e sublimes em virtude de palco off instalado à pressa "na baiúca fedorenta do Mal Cozinhado", que, por decreto de Camões, passaria a ser "o Olimpo dos Deuses" (Gralheiro, 1983: 42).

Uma outra marca de estranhamento é ainda a música que, cantada ao longo da obra, por exemplo, quando Camões entoa os sonetos Amor é fogo que arde sem se ver e Mudam-se os tempos, mudam as vontades (o último, em forma um tanto reefabulada), a cantiga Perdigão perdeu a pena ou a Autopsicografia de Pessoa, como também a falsa 'redondilha' Quem bate/no Vate? , acompanhado das meretrizes e dos rufiões, confere aos poemas (verdadeiros ou inventados por Jaime Gralheiro) um tom paródico e grotesco, de ritmo sincopado, cujo texto é mais falado ou salmodiado do que cantado. Camões canta, sim, na peça de Jaime Gralheiro, metido na cadeia e acusado do criptojudaísmo, ou melhor, "por causa daquela estocada em Gaspar Borges, no dia do Corpo de Deus" (1983: 88). A vida de Camões encobre, pois, mais factos conjeturados do que comprovados.

Queimada Esperança, a namorada de Camões, num auto-de-fé, o poeta embarca para a Índia (no início da cena segunda do ato segundo). Antes ainda, aparece um Velho (com certeza, é um avatar do Velho do Restelo!) e recita as oitavas 94 e 96 do canto IV de $O s$ Lusíadas, introduzidas no corpo da peça sem aspas, marcação textual essa que mereceu umas duas quadras de suposta autoria camoniana, inseridas nas falas de Uma Velha e de Uma Mulher, "com cabelos ao vento...". Sem definir a qualidade das imitações (transcrições, paródias, disfarces) camonianas presentes na peça de Jaime Gralheiro, 
invocaremos a intertextualidade enxertada d'Os Lusíadas como propriedade constitutiva do texto dramático em causa.

Outras citações épicas ainda vão perpassar o ...Onde Vaz Luís?, na sétima cena do terceiro ato, escamoteando um tanto o significado da Proposição - introdução da obra, da dedicatória ao Rei D. Sebastião e da invocação às Tágides do canto I e a Calíope do canto III da epopeia camoniana, entremeadas com alguns gritos do protagonista encarcerado na masmorra do Santo Ofício. É, pois, no cárcere que o vate lusitano evoca agora a falecida Dinamene, uma jovem chinesa que arrebatou o luso coração ainda além da Taprobana ${ }^{7}$, e chora as suas desventuras, "perdido nas costas da China ... sem ninguém ... com um livro na mão"(Gralheiro, 1983: 130). Os Lusiadas funcionam ainda como a súmula do imaginário identitário português ou da identidade coletiva portuguesa. Portugal "orgulhosamente só", assume a sua qualidade de "cabeça da Europa" (1983: 32) ${ }^{8}$, retoma-se o tópico da pátria ingrata e metida "no gosto da cobiça e na rudeza" (Camões, 1988: 145) referida na oitava 146 do canto décimo do hipotexto camoniano (Os Lusíadas, X, 146, 7) e na oitava cena do último acto da peça de Jaime Gralheiro.

Há, ainda, muitas outras referências à epopeia lusa, referências essas diluídas no texto dramático, absorvidas por completo como citações não anotadas ou imitadas livremente remetendo para o conceito de arquitextualidade camoniana ou da classe dos modos, géneros ou

${ }^{7}$ Luís Vaz de Camões sempre teve uma vida amorosa atribulada (de que oportunamente falámos) e, trota-mundos por natureza, apaixonou-se por uma Dinamene, ou melhor, Tin Nam Men, uma jovem chinesa. Da relação pouco se sabe, mas pelos sonetos de Camões calcula-se que essa alma gentil seria a musa inspiradora do imortal poeta. Como tudo na vida de Camões, o amor não acabaria bem. Conta a lenda, referida pelos primeiros biógrafos camonianos (Pero de Mariz e Severim de Faria), que o navio onde o casal navegava naufragou e, entre salvar a sua amada musa ou a sua amada epopeia, Camões preferiu salvar Os Lusiadas.

${ }^{8}$ Cf. "Eis aqui, quase cume da cabeça/ De Europa toda, o Reino Lusitano,/ Onde a terra se acaba e o mar começa/ E onde Febo repousa no Oceano", Camões, Os Lusiadas, III, 20, 1-4 (1988: 123). 
subgéneros literários que relacionam a obra com as diversas classes de inter e hipotextos camonianos. Sendo assim, o poema épico ou um soneto (ou um poema na medida velha) tem uma relação de arquitextualidade com a classe de peças de teatro, obras líricas e contos (como os contos de José Luís Peixoto concebidos em 2013 para resumir e contar de novo Os Lusíadas) que nos permitem falar, sem incorrer em classificações rígidas e normativas dos modos e dos géneros literários, sobre a especificidade sui generis da herança de Camões, eminentemente social, cultural, literária e política, produtora dos textos que se prendem com a conceção da linguagem como um jogo intertextual (Reis; Figueiredo, 1999: 49). Assim se reescreveu e desdobrou em versões contemporâneas de Outro "o épico da raça lusíada" chamado Luís Vaz de Camões.

O choque de conhecer (ou não conhecer...) a obra de Camões passa ao choque do (não) conhecer o passado de Portugal. Da acumulação de incompreensibilidades surgirá a compreensão de uma realidade estranha às façanhas heróicas, às virtudes de homens, mulheres e guerreiros que há muito tempo deixaram de ser nobres, independentemente do tempo em que viveram ou do teatro das ações que pisaram: do século XVI, do século XIX ou mesmo dos séculos XX e XXI. O narrador, percorrendo as cenas e atravessando os tempos com as suas vontades de negar, chocar, ofender e minar tudo o que ainda não estoirou ou, por assim dizer, não perdeu o prazo de validade ideológica, nem sequer da perceção imediata da realidade, metamorfoseia-se em várias outras personagens: o cauteleiro, o pregoeiro da feira, o leiloeiro, o chefe da trupe de saltimbancos, o falso frade, o pedinte, o escravo de Camões, e, por fim, fechando o círculo narrativo, retorna à função do cego cauteleiro do início da peça, "em Lisboa de hoje". É o momento diegético esse, na última (nona) cena do ato terceiro, quando Camões "acabrunhado" se encontra no centro, junto à casa de Fernão Mendes Pinto, abordado pelos "bufos" (polícias secretos ou delatores) da Inquisição, representados também no Mal-Cozinhado.

Condenado Damião de Góis à prisão perpétua, à confiscação de toda a fazenda e ainda à pena de excomunhão, chegada a notícia sobre a derrota de D. Sebastião em Alcácer-Quibir (1578), tombam as 
bandeiras, Camões recita o seu último canto, de acusação aos vindouros, cai também e morre, como o seu homólogo de Almeida Garrett no poema homónimo (Camões, 1825). O escravo lamenta-se de que "ninguém quer comprar os versos de Camões" (Gralheiro, 1983: 155) e, de acordo com a informação da útlima nota didascálica, "transforma-se no vendedor de cautelas da $1^{\text {a }}$ Cena do 1 Acto" (1983: 155). Começa a lotaria de Camões, do ano de mil novecentos e oitenta, é de supor que organizada pela ocasião do Dia de Camões e das comunidades portuguesas espalhadas pelo mundo. A lotaria intertextual essa, difícil de destrinçar sem o conhecimento do passado, do presente, do verdadeiro e do discurso do (im)poder ou o discurso oficial e o discurso calado.

\section{O discurso camoniano do (im)poder ou o poder do discurso de Camões}

$\mathrm{Na}$ última cena da peça de Jaime Gralheiro, quando, pela boca do fiel escravo, já sabemos que (assim hoje como outrora..., quem sabe) "ninguém quer os versos de Camões", um momento antes de morrer, o poeta lusitano acorda, soerge-se no seu pobre catre e "dirige-se aos seus contemporâneos" no dorido discurso de imprecações e vitupérios, profetizando "outros ladrões" ainda a porem flores no seu túmulo (cf. Sena, 1988: 95), agora com a óbvia alusão à revolução dos cravos (25.04.1974):

CAMÕES: Se te disserem que morro de fome... diz-lhes que morro de nojo...

A minha pátria amada não é esta.

Tudo me quiseram roubar ... Vai e diz-lhes que, um dia, tudo será meu... E, então, eles levantarão o meu espantalho e farão dele uma bandeira ... Canalhas!...

Essa é a bandeira da mentira.

Eu sou o espaço da contradição: o tempo da verdade!

Da miséria em que morro, há-de florir um cravo!

\footnotetext{
${ }^{9}$ Ibidem.
} 
E a minha pátria fica à espera para colhê-lo.

(Gralheiro, 1983: 156).

No desfecho da peça, Camões é apresentado de forma condizente com a sua vida e morte, sem posses e na penúria. Consta que o autor de Os Lusíadas nunca fora reconhecido como grande poeta em vida, sempre foi dono de um estilo de vida boémio e terminou a sua vida na extrema miséria (em Lisboa, em 10 de junho de 1780, segundo a versão mais provável). Teve de implorar pela tença ao rei D. Sebastião também protagonista da peça de Jaime Gralheiro e o seu narratário, ou o leitor inscrito na obra/the implied reader, quanto à imitação quase perfeita da dedicatória épica recitada pelo autor ficcional, para que Os Lusiadas fossem publicados com o imprimatur do Santo Ofício. Na peça coeva de José Saramago (Que Farei com Este Livro? 1980), a função do oficial inquisitorial passou do Cardeal D. Henrique, o Grande-Inquisidor para o Frei Bartolomeu Ferreira, uma outra máscara portátil e historicamente verosímil de uma bófia pidesca. A pergunta ficou a mesma:

LUÍS DE CAMÕES: Que farei com este livro? (...) Que fareis [Vós] com este livro?

VOZ FEMININA: Os Lusíadas...

VOZ MASCULINA: ... de Luís de Camões

VOZ FEMININA: ... Canto Primeiro...

VOZES EM CORO: As armas e os barões assinalados/ Que, da Ocidental praia Lusitana, /Por mares nunca dantes navegados.

(Saramago, 1998: 174-175).

Na nossa leitura das duas peças camonianas do início da década de 80 do século passado reside, como quisera Luiz Francisco Rebello no Prefácio (talvez) supérfluo à peça saramaguiana, a superação do conflito ideológico, cultural e também textual em que as obras foram geradas, e, antes de mais nada, "o trânsito para o futuro" (Rebello ap. Saramago, 1998: 15), ainda possível, do povo português, dos leitores, tradutores e imitadores de Os Lusíadas. 
A peça de Jaime Gralheiro foi construída sob a égide da história que ficou à margem de um Camões (assim como de outros protagonistas dos Quinhentos em Portugal) desmistificado e destituído de glorificação, visão contrária àquela que sempre foi imposta pelo discurso oficial do poder. Na cena IX do segundo ato, reitera-se a dicotomia entre Camões e Fernão Mendes Pinto. O diálogo travado entre os dois escritores retoma a ideia que percorre a peça, de que o poema camoniano "não é o canto da vossa arraia miúda, mas dos heróis... dos reis...daqueles que fizeram Portugal e se foram à Índia e deram novos mundos ao mundo..." (Gralheiro, 1983: 139). Fernão Mendes Pinto contrapõe Camões ao afirmar que a sua Peregrinação (1614) ${ }^{10}$ vai cantar, sim, a "arraia miúda" que, diferentemente dos reis e "dos grandes senhores que ficam em Lisboa" (Gralheiro, 1983: 139), foi à Îndia descobrir novas terras.

O diálogo entre Camões e Fernão Mendes Pinto representa o discurso do poder em oposição ao discurso calado por conveniência, formulado tão-somente no fragmento atrás citado, na última cena da peça. O discurso dos detentores do poder está sendo oposto por Jaime Gralheiro ao anonimato de quem, tendo também feito e participado da história de Portugal é relegado ao esquecimento e que, mesmo assim, consegue estabelecer transitividade discursiva vitalizante da memória de um personagem e do seu meio-ambiente. Discursividade transitiva essa que já foi tentada e está ainda em curso, no campo do romance, representada por António Lobo Antunes, José Saramago Gonçalo M. Tavares e José Luís Peixoto, recuperando criticamente o passado colonial, fascista ou qualquer outro, relacionado com Portugal e o seu passado/presente. A cultura dominante re-contextualiza-se às vezes até

${ }^{10}$ Peregrinação é uma obra literária de Fernão Mendes Pinto (1509-1583) pertencente à chamada literatura de viagens, próxima do que se poderia chamar crónica de viagem ou diário. É o livro de viagens da literatura portuguesa mais conhecido e traduzido. Foi publicado em 1614, em Lisboa, dado à estampa por Pedro Craesbeeck, trinta anos após a morte do seu autor. 
em circunstâncias bíblicas ${ }^{11}$, deixando ver os contornos de uma nova homogeneidade coletiva, cristalizada ao contrário da História oficial.

A cena final do ...Onde Vaz, Luis? representa, assim, uma contradição face à história oficial. Camões é apresentado de modo diferente da cena II do primeiro ato, quando estava a ser louvado pela professora do secundário, pelo político, pelo professor universitário (e gracejado por gerações de alunos!). Nesta cena, o protagonista fala dos problemas que afligem Portugal enganado pelas mentiras de políticos, em que o próprio poeta se torna tanto "o espaço da contradição" como o arauto de "o tempo da verdade", defensor da razão e da experiência feita desta e dos livros que na cena precedente foram confiscados pelo Santo Ofício.

O poeta d'Os Lusíadas no fim das duas peças históricas que lhe foram dedicadas por Jaime Gralheiro e José Saramago toma o lugar do protagonista (ou seria o autor que se torna o ouvinte do poeta? Seria mesmo a ficção mais verdadeira do que a história?) para afirmar que o nevoeiro já se levantou e um cravo há-de reflorir. "Um cravo" que irá reflorir da miséria de Camões não seria o símbolo da Revolução de abril de 1974 que derrubou o regime que vigorava em Portugal desde 1926? Como a Revolução dos Cravos foi a devolução da liberdade ao povo português, o cravo teria sido inserido na peça como instrumento de pedagogia revolucionária, fazendo deste e do outro drama atrás referido uma obra aberta, para citar os conceitos postos a circular por Umberto Eco.

O leitor pós-moderno gostaria verdadeiramente de saber se foi Camões ou Saramago ou Jaime Gralheiro quem teria inventado "mais do que prometia a força humana" (Os Lusíadas, I, 1,6) e, malgrado os esforços dos professores, políticos e outros tantos dirigentes espirituais, sabe de facto a única fórmula, definida por Fernando Pessoa como o NADA de todos os tempos e de todas as verdades. Formulada esta

${ }^{11}$ Exemplo interessante do processo da inserção da obra de J. L. Peixoto no contexto bíblico encontramos na dissertação de mestrado de Maria de Lurdes Lopes Pinho, sobre Intertextualidades bíblicas em Nenhum Olhar (2000), de José Luis Peixoto, Universidade da Beira Interior, Covilhã (ms.), dissertação essa a que devemos a nossa inspiração metodológica do artigo presente (Pinho, 2012). 
pungente questão, logo a transformamos noutra pergunta, que é, afinal, a resposta justa às inquietações dos leitores (pós)modernos de Camões, a quem tornamos a interrogar: Onde Ides? e Que fareis com este livro? e com muitos outros livros em que a teatralização de personalidades exemplares da história literária oscilou entre a narrativa biográfica e o teatro épico-mítico, de cariz Brechteano, “em que a distanciação no tempo funciona como um meio de projectar uma luz reveladora sobre o presente" (Rebello ap. Saramago, 1998: 11).

Nesta perspetiva, Jaime Gralheiro aparece como continuador de tais mestres da dramaturgia portuguesa como Almeida Garrett, António Patrício, Jorge de Sena, José Cardoso Pires, Luís de Sttau Monteiro, Bernardo Santareno, Fiama Pais Brandão, José Saramago e muitos outros escritores que se dedicaram à recriação crítica, verdadeira ou inventada, da História. A revisitação de Camões no teatro português contemporâneo encontra aqui a sua justificação cabal, assim como o vasto (con/hipo)texto da obra e da vida de Luís Vaz.

\section{Referências bibliográficas}

BOUILLAGUET, A. (1996), L'Écriture Imitative: pastiche, parodie, collage, Nathan, Paris.

CAMÕES, L. VAZ de (1988), Os Lusíadas, introd. S. A. Benedito, notas A. Leitão, Ulisseia, Lisboa.

CEIA, C. "Estranhamento (Ostranienie)" em: E-Dicionário dos Termos Literários, [on-line] http://edtl.fcsh.unl.pt/encyclopedia/estranhamento-ostraniene/ - 28.08.2018.

CHKLOVSKI, V. (1999), “A arte como processo” em: Teoria da Literatura I: Textos dos formalistas russos apresentados por Tzvetan Todorov, Edições 70, Lisboa.

CORRADIN, F. M. (2003), "Projeto autor por autor: Camões e Fernão Mendes Pinto vistos por Jaime Gralheiro" em: Atas do $2^{\circ}$ Colóquio do PPRLB: Deslocamentos e Permanências, Rio de Janeiro, [on-line] http://rgpl.mygead.com/OPAC/Register/Index/ba7dc7cb-ef95-4911-b730-afbe939d5cde -3.04 .2019 . 
GENETTE, G. (1982), Palimpsestes. La littérature au second degré, Seuil, Paris.

GENETTE, G. (1995), Discurso da narrativa, trad. F. Cabral Martins, Vega, Lisboa.

GRALHEIRO, J. (1983), ...Onde Vaz, Luís? Vega, Lisboa.

KALEWSKA, A. (2016), “A recepção d'Os Lusíadas e o mito de Camões em Itália e na Polónia” em: Graziani, M., Abbati, O., Gori B. (a cura di), La spugna è la mia anima. Omaggio a Piero Ceccuci, Firenze University Press, Florença, pp. 125-140.

KALEWSKA, A. (1999), Camões, czyli tryumf epiki [Camões, ou o triunfo da poesia épica], Wydawnictwa Uniwersytetu Warszawskiego, Warszawa. KALEWSKA, A. (2019), “As traduções d'Os Lusíadas na Polónia ou a revisitação de Camões entre «os Sármatas» e «os Polónios» (questões históricas, culturais e sócio-políticas)", E-Letras Com(n)Vida. Revista de Humanidades e Artes, 2, Lisboa, pp. 27-45, [on-line] https://e-lcv.online/ index.php/revista/article/view/39 - 28.11.2019.

KAUFMAN, H., KLOBUCKA, A. (eds.) (1997), After the Revolution: Twenty Years of Portuguese Literature, 1974-1994, Bucknell University Press, Lewisburg.

KRIŠTEVA, J. (2000), Sémiotiké. Rechereches pour une semanalyse, Seuil, Paris.

MENDES, A. P. Coutinho (2006), "Katherine Vaz e a re-inscrição de Mariana Alcoforado na história literária" em: Amaral, A. L.; Cunha, G. (orgs.) Homenagem a Margarida Llosa, FLUP, Porto, pp. 293-308, [on-line] http:// ler.letras.up.pt/uploads/ficheiros/4244.pdf. - 13.11.2018.

"Morreu o dramaturgo Jaime Gralheiro de 83 anos", [on-line] https://ionline. sapo.pt/310025 - 13.11.18.

PINHO, M. de Lurdes Lopes, Intertextualidades biblicas em Nenhum Olhar (2000), de José Luis Peixoto (2012), diss. de mestrado (ms.), Universidade da Beira Interior, Covilhã, [on-line] https://ubibliorum.ubi.pt/bitstre$\mathrm{am} / 10400.6 / 3408 / 1 /$ Intertextualidades $\% 20 \mathrm{~b} \% \mathrm{C} 3 \%$ ADblicas $\% 20 \mathrm{em} \% 20$ Nenhum\%20olhar,\%20de\%20Jos\%C3\%A9\%20Lu\%C3\%ADs\%20Peixoto.pdf - 13.11.2018.

REBELLO, L. F., "Prefácio (talvez) supérfluo" em: Saramago, J. (1998), Que Farei com Este Livro? Caminho, Lisboa. 
REIS, C.; FIGUEIREDO, V. de Campos (1995), O Conhecimento da Literatura. Introdução aos Estudos Literários, Universidade Aberta, Lisboa. REIS, C. (2005), História Crítica da Literatura Portuguesa (Do Neo-Realismo ao Post-Modernismo), Verbo, Lisboa, vol. IX.

SARAMAGO, J. (1998, $3^{\mathrm{a}}$ ed.), Que Farei com Este Livro? Caminho, Lisboa. SENA, J. (1988), Poesia II, Edições 70, Lisboa.

SILVA, V. M. de AGUIAR e (2011), Dicionário de Luís de Camões, Leya, São Paulo.

VASCONCELOS, A. I. P. Teixeira de (2003), O drama histórico português do século XIX (1836-56), Fundação Callouste Gulbenkian - Fundação para a Ciência e a Tecnologia, Lisboa.

VIEIRA, C. da Costa (2008), A construção da personagem romanesca: processos definidores, Colibri, Lisboa. 